Research Article

\title{
Risk Factors and Prevention Strategies of Nosocomial Infection in Geriatric Patients
}

\author{
Yajie Li $\mathbb{D}$, Liqun Ren, and Jihong Zou $\mathbb{D}$ \\ Geriatrics Department, Zhongda Hospital Southeast University, No. 87, Dingjiaqiao, Nanjing, China \\ Correspondence should be addressed to Jihong Zou; 18005140682@163.com
}

Received 14 November 2018; Revised 16 January 2019; Accepted 30 January 2019; Published 25 February 2019

Academic Editor: Gabriele Messina

Copyright (c) 2019 Yajie Li et al. This is an open access article distributed under the Creative Commons Attribution License, which permits unrestricted use, distribution, and reproduction in any medium, provided the original work is properly cited.

\begin{abstract}
Introduction. To investigate the risk factors of nosocomial infections (NIs) in geriatric department and the effectiveness of the proposed prevention strategy. Methodology. We studied 3370 cases of elderly patients who were hospitalized more than 48 hours from January 2015 to December 2017 in the Geriatrics Department of Zhongda Hospital, Southeast University. In order to reduce the infection rate, nutritional risk screening (NRS 2002) was used to evaluate the nutritional status of the patients; enteral nutritional suspension (TPF-FOS) was provided to the patients who were assessed to be necessary. Results. Before prevention strategy was taken, the nosocomial infection rate was 3.3\% (80 among 2413 patients) in our department. The most frequent NIs were pneumonia (60 cases) followed by urinary tract infection (30 cases). It is worth noting that the elderly patients are often associated with multiple infections: in our study, 15 patients have pneumonia and UTI at the same time. After prevention strategy was taken, the nosocomial infection rate reduced to $1.15 \%$ (11 among 957 patients) in our department. Conclusions. NIs are common in elderly patients. The improvement of the nutritional status of patients is effective in reducing the risks of NIs.
\end{abstract}

\section{Introduction}

As the largest developing country in the world, China is now facing a serious population aging problem: by 2020, the elderly population is expected to reach 248 million and the aging level to $17.17 \%$, of which 30.67 million will be aged 80 and above [1]. Therefore, it is urgent to improve the evaluation and treatment for elderly patients. However, elderly people are susceptible to infections due to hypoimmunity [2], which is caused by malnutrition, comorbidity, decreased antibody production, delays in their cellular and humoral immune responses, etc. [3]. Especially when elderly patients are hospitalized after 48 hours and exposed to invasive procedures in an environment abundant with virulent and antibiotic-resistant pathogens, the risk of nosocomial infections (NIs) is even higher $[4,5]$.

Despite the fact that the risk for elderly patients to get NIs is obviously higher, the risk factors in geriatric patients are still not well known [6,7]. The aim of this study is to determine the risk factors leading to NI development and discuss the effectiveness of nutrition status improvement in prevention of NIs for elderly patients.

\section{Methodology}

2.1. Study Design. A retrospective analysis was conducted. The distribution of the patient's infection and the pathogenic microorganisms of the infections identified as NIs in the elderly patients are carefully recorded. The age of the patient, sex, length of hospital stay, whether the patient was in bed for a long time, whether the patient combined with chronic diseases, hypoproteinaemia, dysphagia, invasive procedure, etc., were analyzed in detail.

Malnutrition was considered to be one of the main causes of NIs. On admission, based on NRS 2002, the patients were scored according to weight, albumin level, and disease status. If the score is $<3$, no intervention will be taken. If the score is $\geq 3$, daily diet will be supplied according to the required daily calorie calculation formula (energy $=25 \mathrm{kCal} / \mathrm{kg} \cdot \mathrm{d})$; also, enteral nutrition suspension (TPF-FOS) [8] is provided to 
increase energy. Comparative analysis was done between before and after the prevention strategy was taken.

2.2. Clinical Data. Zhongda Hospital, Southeast University, has a database which includes all the medical reports and a real-time hospital infection monitoring system. The data were collected between January 2015 to December 2017 in the Geriatrics Department based on the database and the system.

Before the NI prevention strategy was taken, 2413 hospitalized patients (2015.1-2017.5) including 1294 males and 1119 females were investigated; the patients' age ranged from 65 to 101 years, and the mean age was $82 \pm 7.83$ years. After taking prevention strategy to improve the nutritional status of the patients, 957 hospitalized patients (2017.62017.12) including 506 males and 451 females were investigated; the patients's age ranged from 65 to 103 years, and the mean age was $84 \pm 9.26$ years.

2.3. Diagnosis Criteria. The diagnosis criteria for nosocomial infection is determined in accordance with the criteria for diagnosis of nosocomial infection (trial) promulgated by the Ministry of Health of the People's Republic of China in November 2001 [9].

Nutritional risk screening tool: Nutritional Risk Screening 2002 (NRS 2002) [10], which was recommended by the European Society for Clinical Nutrition and Metabolism (ESPEN), was used to evaluate the nutritional status of the elderly patients.

2.4. Statistical Analysis. The Statistical Package for the Social Sciences version10.0 (SPSS) was used for statistical evaluation: T-test, chi-square tests for univariate, and logistic regression analysis for multivariate were calculated for descriptive statistics. A $p$ value $<0.05$ was considered statistically significant.

\section{Results}

In this study, 3370 patients (age larger than 65 years old) were hospitalized more than 48 hours in the Geriatric Department.

Before nutritional risk screening was taken, NIs were detected in 80 patients among 2413 patients; the infection rate was $3.3 \%$ (80 in 2413 patients). The most frequent distribution is pneumonia (60 cases of infection in 80 patients), followed by urinary tract infection (30 cases of infection). Among them, 15 patients have pneumonia and urinary tract infection at the same time. The details of NIs' distribution according to systems are listed in Table 1.

As shown in Table 2, all 80 patients were sent for examination of pathogens, and 58 strains were detected. Among them, 8 strains were Gram-positive bacteria, dominant with Staphylococcus; 36 strains were Gramnegative bacteria dominant with Pseudomonas aeruginosa, E. coli, and Proteus mirabilis; 14 strains were fungi dominant with Candida albicans and Candida glabrata.
TABLE 1: Distribution of NIs.

\begin{tabular}{lc}
\hline Nosocomial infections & Infected cases $(N=95)$ \\
\hline Pneumonia & $60(63.15 \%)$ \\
Urinary tract infection & $30(31.58 \%)$ \\
Skin and soft tissue infection & $2(2.12 \%)$ \\
Gastrointestinal system & $1(1.05 \%)$ \\
Oral infection & $1(1.05 \%)$ \\
Intraperitoneal infection & $1(1.05 \%)$ \\
\hline
\end{tabular}

TABLE 2: NIs developed by microorganism.

\begin{tabular}{|c|c|}
\hline Microorganisms & Bacterial species (N/N total, \%) \\
\hline $\begin{array}{l}\text { Gram-positive } \\
\text { bacteria }\end{array}$ & $\begin{array}{c}\text { Staphylococcus }(5 / 8,62.5 \%) \\
\text { Excrement enterococcus }(3 / 8,37.5 \%)\end{array}$ \\
\hline $\begin{array}{l}\text { Gram-negative } \\
\text { bacteria }\end{array}$ & $\begin{array}{c}\text { Pseudomonas aeruginosa }(7 / 36,19.4 \%) \\
\text { E. coli }(4 / 36,11.1 \%) \\
\text { Proteus mirabilis }(4 / 36,11.1 \%) \\
\text { Acinetobacter baumannii }(3 / 36,8.3 \%) \\
\text { Klebsiella pneumoniae }(3 / 36,8.3 \%) \\
\text { Stenotrophomonas maltophilia }(3 / 36, \\
8.3 \%) \\
\text { Others }(12 / 36,33.3 \%)\end{array}$ \\
\hline Fungi & $\begin{array}{c}\text { Candida albicans }(5 / 14,35.7 \%) \\
\text { Candida glabrata }(6 / 14,42.9 \%) \\
\text { Candida tropicalis }(2 / 14,14.3 \%) \\
\text { Candida krusei }(1 / 14,7.1 \%)\end{array}$ \\
\hline
\end{tabular}

Comparison from clinical features between the two samples (sample_1 are 2413 patients who were not given prevention, while sample_2 are 957 patients who were scored and provided with enteral nutritional suspension) are listed in Tables 3 and 4 . No statistical significance can be found. After providing enteral nutritional suspension (TPFFOS) to the patients according to the screening results, the infection rate for sample_2 was reduced to $1.15 \%$ (11 in 957 patients). Statistical significance is observed in Table 5, and the $95 \%$ CI is $0.180 \sim 0.640$.

Risk factors of NIs such as long-term bed ( $>30$ days of hospitalization), combined with chronic diseases, existence of invasive procedures, malnutrition (score $\geq 3$ ), dysphagia, and so on were taken into consideration. The univariate analysis results showed that long-term bed, malnutrition, invasive procedures, dysphagia, and length of stay are all possible factors in developing NIs (see Table 6).

Multivariate analysis of the risk factors is shown in Table 7. The probability of NIs based on long-term bed, nutrition status, dysphagia, invasive procedure, and length of stay is less than 0.01 . Therefore, they can be used to predict NIs in our department.

\section{Discussion}

In this study, before infection prevention strategy was taken, the incidence of NIs is $3.3 \%$, and the hospitalized duration in our Geriatric Department for per patient is 11 days. The incidence rate is similar to [11] (2.49 per 1000 patient days). The mortality rate is $5 \%$ (4 patients died among 80 nosocomial infected patients), while during the same period, for 
TABLe 3: Analysis of two samples before and after improving of nutrition status.

\begin{tabular}{lccc}
\hline & Age & $p$ value $(p<0.05)$ \\
\hline Sample_1 & $82 \pm 7.83$ & 0.716 \\
Sample_2 & $84 \pm 9.26$ & \\
\hline
\end{tabular}

TABLE 4: Analysis of two samples before and after improving of nutrition status.

\begin{tabular}{|c|c|c|c|c|}
\hline Variate & Two samples & Number/total number & $\chi^{2}$ & $p$ value $(p<0.05)$ \\
\hline Sex (male) & $\begin{array}{l}\text { Sample_1 } \\
\text { Sample_2 }\end{array}$ & $\begin{array}{c}1294 / 2413 \\
506 / 957\end{array}$ & 0.156 & 0.693 \\
\hline Long-term bed & $\begin{array}{l}\text { Sample_1 } \\
\text { Sample_2 }\end{array}$ & $\begin{array}{c}212 / 2413 \\
92 / 957 \\
\end{array}$ & 0.572 & 0.450 \\
\hline Nutrition scores $(\geq 3)$ & $\begin{array}{l}\text { Sample_1 } \\
\text { Sample_2 }\end{array}$ & $\begin{array}{c}132 / 2413 \\
61 / 957\end{array}$ & 1.037 & 0.309 \\
\hline Dysphagia & $\begin{array}{l}\text { Sample_1 } \\
\text { Sample_2 }\end{array}$ & $\begin{array}{c}174 / 2413 \\
71 / 957\end{array}$ & 0.044 & 0.834 \\
\hline Invasive procedure & $\begin{array}{l}\text { Sample_1 } \\
\text { Sample_2 }\end{array}$ & $\begin{array}{c}672 / 2413 \\
239 / 957\end{array}$ & 2.872 & 0.090 \\
\hline Length of stay ( $\geq 30$ day) & $\begin{array}{l}\text { Sample_1 } \\
\text { Sample_2 }\end{array}$ & $\begin{array}{c}77 / 2413 \\
19 / 957\end{array}$ & 3.599 & 0.058 \\
\hline Combined with chronic disease & $\begin{array}{l}\text { Sample_1 } \\
\text { Sample_2 } \\
\text { Sample_2 }\end{array}$ & $\begin{array}{c}1259 / 2413 \\
529 / 957 \\
11 / 957\end{array}$ & 2.646 & 0.104 \\
\hline
\end{tabular}

TABLE 5: Analysis of two samples before and after improving of nutrition status.

\begin{tabular}{lccc}
\hline & With NIs (number/total number) & $\chi^{2}$ & $p$ value $(p<0.05)$ \\
\hline Sample_1 & $80 / 2413$ & 12.235 & $<0.05$ \\
Sample_2 & $11 / 957$ & & \\
\hline
\end{tabular}

TABLE 6: Analysis of risk factors of nosocomial infection in geriatric patients.

\begin{tabular}{|c|c|c|c|c|c|}
\hline \multicolumn{2}{|c|}{ Personal characteristics } & Number & Infected patients & $x^{2}$ & $p$ value $(p<0.05)$ \\
\hline \multirow[t]{2}{*}{ Sex } & Male & 1800 & 48 & \multirow{2}{*}{0.017} & \multirow[t]{2}{*}{0.897} \\
\hline & Female & 1570 & 43 & & \\
\hline \multirow{2}{*}{ Long-term bed } & Yes & 304 & 52 & \multirow{2}{*}{263.896} & \multirow{2}{*}{$<0.01$} \\
\hline & No & 3066 & 39 & & \\
\hline \multirow{2}{*}{ Combined with chronic disease } & Yes & 1788 & 49 & \multirow{2}{*}{0.023} & \multirow{2}{*}{0.878} \\
\hline & No & 1582 & 42 & & \\
\hline \multirow{2}{*}{ Nutrition scores } & $<3$ & 3177 & 69 & \multirow{2}{*}{58.959} & \multirow{2}{*}{$<0.01$} \\
\hline & $\geq 3$ & 193 & 22 & & \\
\hline \multirow{2}{*}{ Dysphagia } & Yes & 245 & 15 & \multirow{2}{*}{11.777} & \multirow{2}{*}{$<0.01$} \\
\hline & No & 3125 & 76 & & \\
\hline \multirow{2}{*}{ Invasive procedure } & Yes & 911 & 37 & \multirow{2}{*}{8.804} & \multirow{2}{*}{$<0.01$} \\
\hline & No & 2459 & 54 & & \\
\hline \multirow{2}{*}{ Length of stay (day) } & $\geq 30$ & 96 & 19 & \multirow{2}{*}{109.863} & \multirow{2}{*}{$<0.01$} \\
\hline & $<30$ & 3274 & 72 & & \\
\hline
\end{tabular}

elderly patients without NIs, the mortality rate is $2.27 \%$ (53 patients died among 2333 patients). The high risk of NIs for elderly patients indicates that the infection control measures are necessary.
The distribution of NIs in geriatric patients was examined, and the most common infection in our hospital is pneumonia, which is the same as $[6,12,13]$. However, compared to the former research studies, the frequency of 
TABLE 7: Multivariate analysis of risk factors of nosocomial infection in geriatric patients.

\begin{tabular}{lcccc}
\hline Variate & Wald & $p$ value & OR & $95 \%$ CI \\
\hline Long-term bed & 5.181 & 0.023 & 2.484 & $1.135 \sim 5.473$ \\
Nutrition scores $(\geq 3)$ & 8.844 & $<0.01$ & 3.463 & $1.527 \sim 7.852$ \\
Dysphagia & 16.898 & $<0.01$ & 7.909 & $2.951 \sim 21.202$ \\
Invasive procedure & 10.567 & $<0.01$ & 1.181 & $1.064 \sim 1.507$ \\
Length of stay (day) & 117.953 & $<0.01$ & 94.565 & $41.608 \sim 214.921$ \\
\hline
\end{tabular}

our study $(63.15 \%)$ is a little too high compared to other developing or developed countries (43\% in [2] and $45 \%$ in [4]); this may have some relation with the nowadays bad air condition in China. Since the mortality of nosocomial pneumonia in Asian countries is very high [14], lots of attention should be paid.

Urinary tract infection is one of the most common nosocomial infections around the world [2, 15-17], and UTI is the secondary common infection in our study. Since UTI is usually the result of placing and removing indwelling urinary catheters; more attention should be paid continuously.

Totally, 58 strains of pathogens were isolated, of which 36 (62.07\%) were Gram-negative bacteria, 8 (13.79\%) were Gram-positive bacteria, and 14 (24.14\%) were fungi; Pseudomonas aeruginosa, E. coli, and Proteus mirabilis were dominant among the Gram-negative bacteria; Staphylococcus was the predominant species of the Gram-positive bacteria; Candida albicans and Candida glabrata were dominant among the fungi. The distribution of the microorganisms is similar to the research in our country [18]. Since in geriatric department, common antibiotic treatment and routine treatment are difficult to get rid of the pathogen completely. Newly developed disinfecting techniques $[19,20]$, like UVC LEDs can be used together to reduce bacterial contamination and against common microorganisms.

Geriatric Department in our hospital has a higher NI rate than other units. This is related with the older age and relative longer duration of hospitalization of our patients. Our research also revealed that invasive procedures, malnutrition, long-term bed, dysphagia, and length of stay are all statistically significant in causing NIs. If the elderly patients stay in the hospital for more than 30 days, the risk of infection will increase greatly; this is because patients with long hospitalization are prone to cross infection [21]. Dysphagia is another significant influence factor for NIs [22], since patients with dysphagia are prone to eating cough and gastrointestinal dysfunction, which will lead to food reflux in the stomach and lung infection. Patients with dysphagia should be given a gastric tube, and the head of the bed needs to be raised while patients are sleeping. Long-term bed is also a risk factor, for bedridden patients; turning over frequently or real-time monitoring system maybe necessary [23]. These specific factors should draw enough attention in the development of infection control measures.

Elderly patients are at high risk of infection, and malnutrition maybe one factor with particularly importance. The result of our research is similar to the cases in the USA
[2] and our country [21, 22]. Also in [2], it is uncertain whether a specially designed program for preventing infections in elderly patients is required. But through our research, after studying two similar samples, using already existing nutrition risk screening tools such as NRS 2002 to score the patients, and improving the nutrition status of the elderly patients with enteral nutritional suspension (TPFFOS), the NIs in elderly patients can be effectively prevented. So in order to reduce the infection rate, poor nutrition of elderly patients should be controlled; procedures such as assessing the nutritional status of the patient and strengthening gastrointestinal nutrition, etc., are perhaps the most effective methods at present.

\section{Conclusion}

In conclusion, NIs are common in geriatric department, and the most common infections are pneumonia and urinary tract infection. Considering the high risks, infection control efforts for pneumonia and UTI should continue to be an important program priority. For the infected patients, pathogens include Gram-positive bacteria, Gram-negative bacteria, and fungi. The empirical treatment decisions in geriatric department can be based on those pathogens. Through our research, long-term bed, malnutrition, invasive procedures, dysphagia, and length of stay are all independent risk factors for NIs in elderly patients. The improvement of nutrition status is important and perhaps one of the few feasible strategies that can be taken in infection control and has been proved to be effective in this paper.

Because this paper is a retrospective analysis, the evaluation of nutritional status before and after nutrition intervention is not comprehensive enough, which will be improved in the future research.

\section{Data Availability}

The data used to support the findings of this study are available from the corresponding author upon request.

\section{Conflicts of Interest}

The authors declare that they have no conflicts of interest.

\section{Acknowledgments}

This work was financially supported by Nanjing Science and Technology Development Guidance Project, China (no. 2015ZD008).

\section{References}

[1] Z. Wang, T. Sun, and G. Li, "Regional differences and evolutions of population aging in China," Population Research, vol. 37, no. 1, pp. 37-42, 2013.

[2] T. G. Emori, S. N. Banerjee, D. H Culver et al., "Nosocomial infections in elderly patients in the United States, 1986-1990. National nosocomial infections surveillance system," American Journal of Medicine, vol. 91, no. 3B, pp. 289S-293S, 1991.

[3] T. Beger, "Infectious diseases in the elderly," Clinical Development, vol. 17, pp. 84-89, 2004. 
[4] A. Inci, "Investigation of nosocomial infections in geriatric patients and newborns," European Journal of Health Sciences, vol. 1, no. 3, pp. 105-108, 2015.

[5] R. M. Ribas and P. P. Gontijo Filho, "Comparing hospital infections in the elderlyversus younger adults: an experience in a Brazilian University Hospital," Brazilian Journal of Infectious Diseases, vol. 7, no. 3, pp. 210-215, 2003.

[6] A. Inci, A. Karabay, S. Erus, and Y. Demiraran, "Nosocomial infections and associated risk factors in geriatric patients in the intensive care unit," Eurasian Journal of Emergency Medicine, vol. 15, pp. 177-180, 2016.

[7] B. B. Yavuz, "Geriatric evaluation and tests," Internal Medicine Journal, vol. 14, pp. 15-17, 2007.

[8] S. Dba, "Response to "enteral formulas in nutrition support practice: is there a better choice for your patient?"," Nutrition in Clinical Practice: Official Publication of the American Society for Parenteral \& Enteral Nutrition, vol. 32, no. 3, p. 430, 2017.

[9] Ministry of Health of the People's Republic of China, "Diagnostic criteria for nosocomial infection," Chinese Journal of Medicine, vol. 81, no. 5, pp. 314-320, 2001.

[10] J. Kondrup, S. P. Allison, M. Elia, B. Vellas, and M. Plauth, "ESPEN guidelines for nutrition screening 2002," Clinical Nutrition, vol. 22, no. 4, pp. 415-421, 2003.

[11] M. Avci, O. Ozgenc, S. A. Coskuner, and A. I. Olut, "Hospital acquired infections (HAI) in the elderly: comparison with the younger patients," Archives of Gerontology and Geriatrics, vol. 54, no. 1, pp. 247-250, 2012.

[12] K. Ozdemir, M. Dizbay, and A. Dikmen, "Incidence and risk factors of nazocomial infections in elderly and adult patients in intensive care units," Turkish Journal of Geriatrics, vol. 16, pp. 155-160, 2013.

[13] F. Stéphan, A. Cheffi, and F. Bonnet, "Nosocomial infections and outcome of critically ill elderly patients after surgery," Anesthesiology, vol. 94, no. 3, pp. 407-414, 2001.

[14] B. Cao, T. T. Tan, E. Poon et al., "Consensus statement on the management of methicillin-resistant Staphylococcus aureus nosocomial pneumonia in Asia," Clinical Respiratory Journal, vol. 9, no. 2, pp. 129-142, 2014.

[15] L. Oberoi, N. S. Neki, R. Kaur, and R. Oberoi, "Changing trends of nosocomial infections in geriatric patients in a tertiary care hospital," Journal of Internation Medical Sciences Academy, vol. 25, pp. 233-234, 2012.

[16] R. Girard, S. Gaujard, V. Pergay, P. Pornon, G. MartinGaujard, and L. Bourguignon, "Risk factors for urinary tract infections in geriatric hospitals," Journal of Hospital Infection, vol. 97, no. 1, pp. 74-78, 2017.

[17] Y. Wang, H. Zhang, and J. Ren, "Nursing and multivariate logistic regression analysis of risk factors for hospital acquired infection of the senile patients," Chinese Journal of general practice, vol. 8, no. 11, pp. 1467-1468, 2010.

[18] M. Y. Li, M. Jin, H. C. Ling, Y. Xia, and Y. H. Tao, "Risk factors for nosocomial infections in patients of psychogeriatric department and distribution of pathogens," Chinese Journal of Nosocomiology, vol. 10, pp. 1-4, 2017.

[19] G. Messina, M. Fattorini, N. Nante et al., "Time effectiveness of ultraviolet $\mathrm{C}$ light (UVC) emitted by light emitting diodes (LEDs) in reducing stethoscope contamination," International Journal of Environmental Research and Public Health, vol. 13, no. 10, p. 940, 2016.

[20] G. Messina, E. Ceriale, D. Lenzi, S. Burgassi, E. Azzolini, and Manzi, "Environmental contaminants in hospital settings and progress in disinfecting techniques," BioMed Research International, vol. 2013, Article ID 429780, 8 pages, 2013.
[21] Z. Xu, X. M. Liang, X. Z. Jiang, and X. J. Lin, "Infection status in aged disease department of hospital and infectious risk factor analysis," Nursing Practice and Research, vol. 13, no. 4, pp. 94-95, 2006.

[22] R. H. Yang and R. H. Zhou, "Clinical study of the impact of early enteral nutrition on nosocomial infections in elderly patients with chronic respiratory diseases," China Modern Doctor, vol. 51, no. 33, pp. 36-38, 2013.

[23] H. Nakajima, M. Takahashi, K. Saito, and K. Ito, "Development of RFID antenna for detection of urination," IEICE Transactions on Communications, vol. E96-B, no. 9, pp. 2244-2250, 2013. 


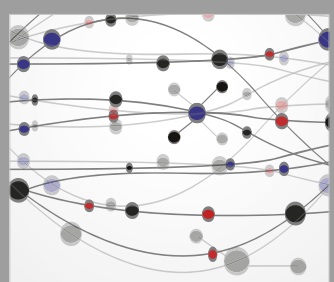

The Scientific World Journal
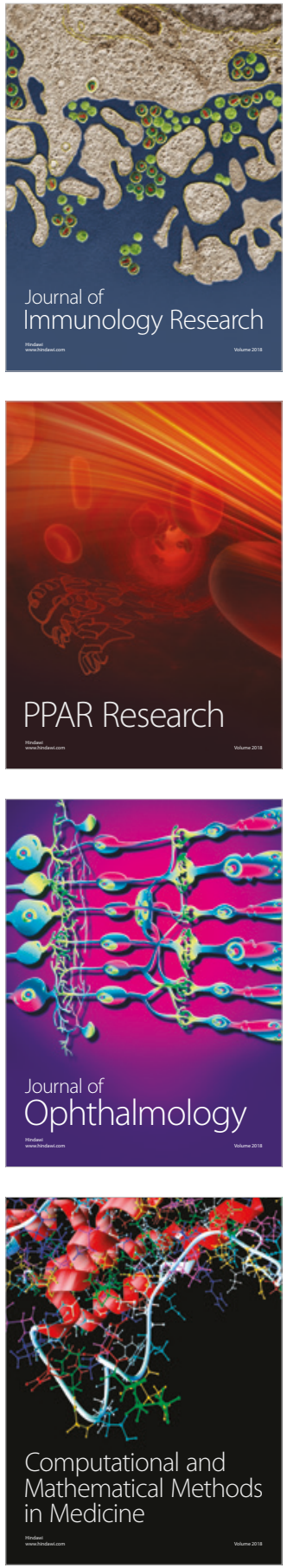

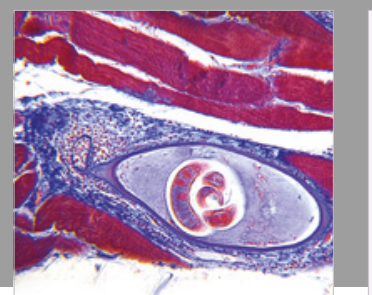

Gastroenterology Research and Practice

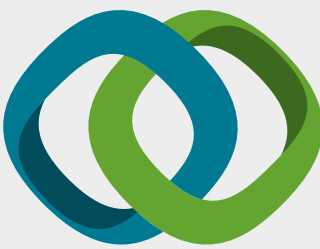

\section{Hindawi}

Submit your manuscripts at

www.hindawi.com
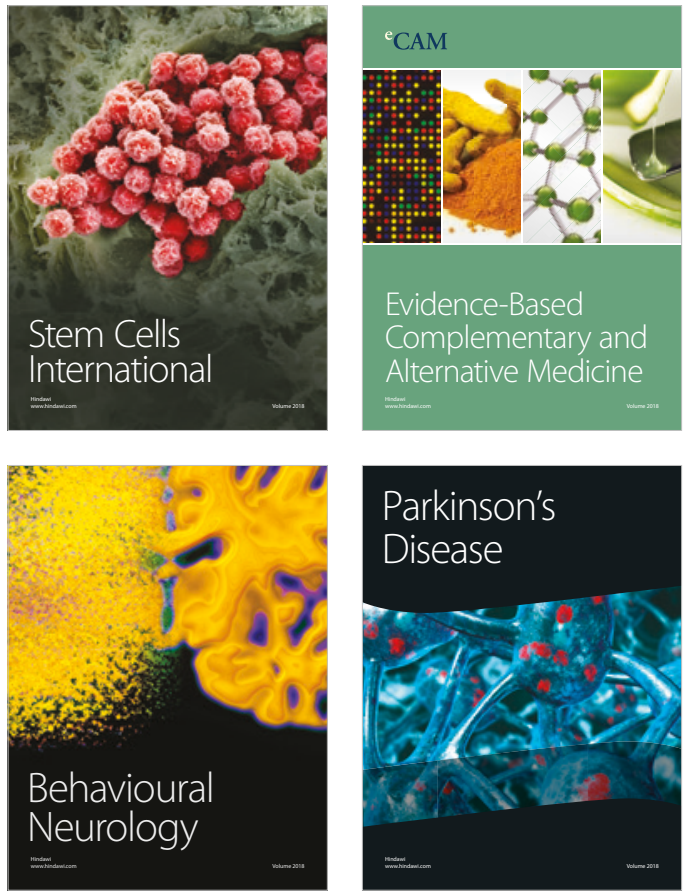

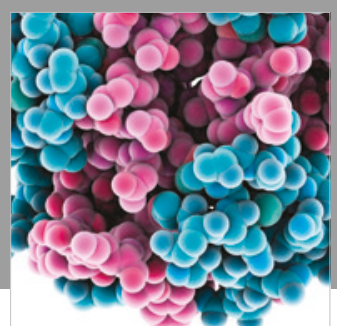

ournal of

Diabetes Research

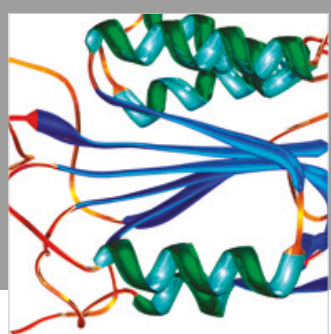

Disease Markers
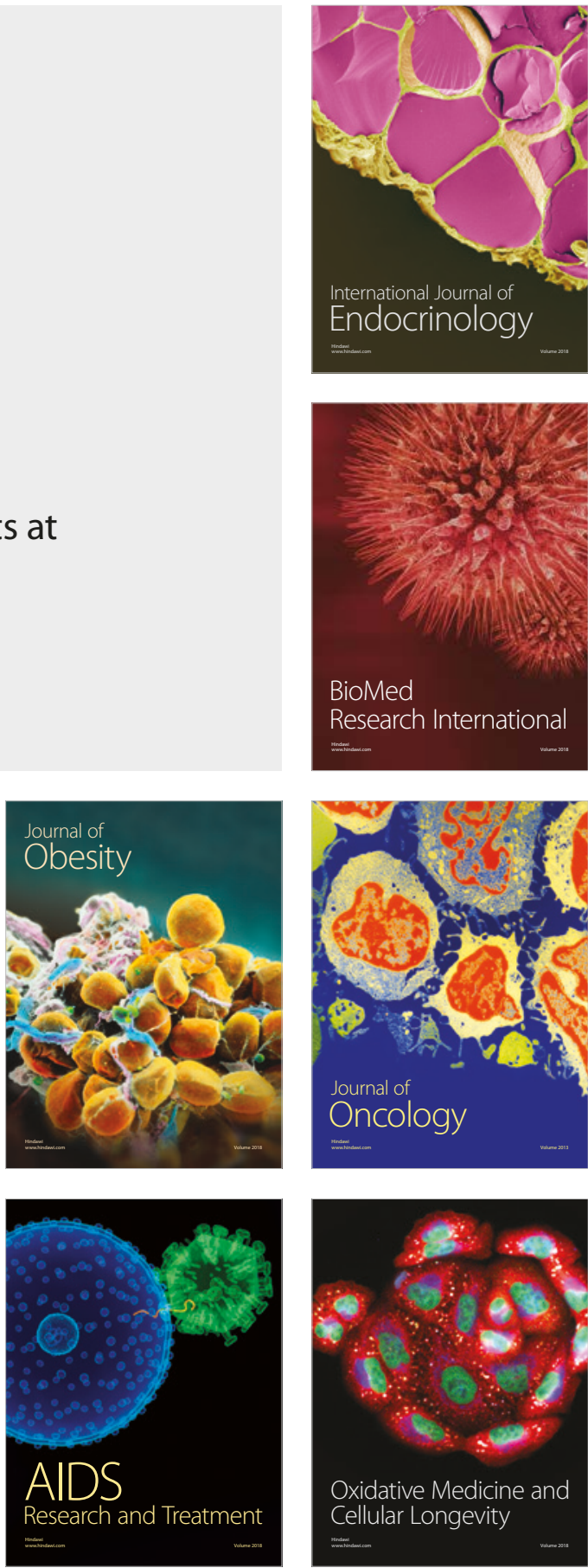